\title{
A Study of the Vitality of Xiandao Language (Atsang Dialect) Relative to Global Language Loss
}

\author{
YUAN Yan \\ Yunnan University, Kunming, China
}

\begin{abstract}
In the world today, there are many reasons causing language loss, among which the contact and mixing of languages is the main reason. This paper focuses on the study of a small ethnic group, Xiandao, and their language vitality. By two months' field work at the village of Xiandao, which locates at the border area between Myanmar and Yunnan, China, the author had door by door interview and showed by statistics in the paper. Firstly, the classical study that it takes at least three generations for a language to shift is not true among the village. The language loss of Xiandao is going faster. Secondly, it is usually dominant official language that minority people choose to shift. Yet it is not the cause in Xiandao. Thirdly, the United Nations Educational Scientific and Cultural Organization's (UNESCO’s) evaluative factors of language vitality are not very helpful to evaluate the Xiandao language. Finally, the author suggested that government train at least one scholar of each language so to help with their own language and culture.
\end{abstract}

Keywords: Xiandao, language loss, vitality, endangered language

\section{Introduction}

\section{Language Loss in the World}

Linguists estimate the rate of language extinction is one language in the world every two weeks. According to their estimates, there were about 150,000 kinds of languages in the world before Christ. By the Middle Ages, this was reduced to 7,000 to 8,000 languages. Since the 1980 's, this phenomenon of language has accelerated. By the beginning of the 20th century, there were 6,000 to 7,000 left. It is currently predicted that $70 \%$ to $80 \%$ of remaining languages will lose their functions to be replaced by the official languages. Language extinction has happened over the course of human civilization, but the present speed of language loss is unprecedented. Viewed from the history of language development, the number of the world languages is lessening.

As globalization and economic integration accelerate, communications are internationalized, spanning ever wider distances, moving faster. Recent advances in information technology have dramatically closed the distance between different regions and countries, and with this the links between peoples are being enhanced. With the development of the internet and telecommunication revolution, the world becomes smaller and smaller, the distance becomes shorter and shorter, and the people become closer and closer. It is the process that necessitates people to face the world instead of just keeping going on with their tradition and giving up themselves to the

YUAN Yan, professor, Ph.D., College for International Students, Yunnan University. 
society. Dominant languages and culture are big thread to disadvantaged languages and culture. Language loss is an overwhelming world trend, no matter from Australia in the southern globe to Siberia in the northern globe, or from plain Oklahoma of US to mountainous Yunnan of People's Republic of China (PRC).

\section{Language Situation in China}

China is a country with different nationalities. There are 56 nationalities in all, among which 55 are minorities which stand for about $8 \%$ of the total. Han is the majority. Among the minority nationalities, only Zhuang's population is over 10 million, 17 minorities are with the population between one million to 10 million, 15 minorities between 100 thousand to one million and 15 minorities between 10 thousand to 100 thousand. There are about 10 minorities with the population less than 10 thousand. Besides the 55 minorities, there exist some even smaller groups which are called un-identified groups. For example, at the bordering area of Yunnan, southwest of China, there are another 10 with the population of several tens or several hundreds.

The 55 minority nationalities in China speak about 130 languages. About 100 of them are without written forms. Minority people are economically less developed than Han people, and minority areas are not so developed as areas inhabited by Han people. In the process of modernization after reform and opening to the outside world in the 80s last century, the communications between different areas and different nationalities are expanded and accelerated. Mandarin Chinese becomes more and more important to them. It was at least from the late 80s and the beginning of 90s that the traditional culture of minority people in China became seriously endangered. Minority languages are facing the challenge caused by Mandarin Chinese, Chinese dialect, and even English. Traditional ballads, legends, and heroic poetry have been lost. Languages, ceremonies, and customs are being deserted. Metropolitan language dominates over others.

Chinese linguists divide the languages which do not have so much vitality into tow levels: "endangered language” (濒危语言) and “dying language” (濒绝语言). Endangered language refers to the language with less and less vitality. Most of the native children do not speak it any longer though some still use, but they are bilinguals. Their second language ability is better than their mother tongue. After tens of years later, only a few aged people can use freely. Nearly 30 languages belong to this level. Dying language refers to the language that all children do not use any more in the village. The adults can speak, but they use adopted language more often. Dying languages will disappear within the 20s. Nearly 10 languages are said to be dying languages in China.

\section{Meaning of Language}

When people study a second language, everyone will find something that he cannot be expressed in the first language. Languages are not only tools, but also the carriers of culture and the identity of the people. Of the language with no writing, all the culture, history, religion, and other information are stored in their languages. With the loosing of the language, almost all the highlights of their culture cannot be touched any more. Language is linked with its identity. With the loss of a minority's language, their main identity leaves us at the same time.

Different languages have helped us human kinds to discover the world more precisely as different people experience the world differently. It is said there are 50 different worlds which mean snow in a Canadian language. If you have not been to the area of Atsang people, you may wonder why "cloud" and "fog" are the same word in their language. If you do not get into their culture, you will not know why "grass” and "bamboo" are expressed in 
so many forms. Take another language as an example, there are more than 10 to 20 verbal prefixes meaning direction in the language spoken by Pumi nationality in Yunnan. One cannot understand until he sees in person that it is because they live in the valley of high mountains that their action and behavior are so closely connected to the direction of mountains and rivers. So verbs are always used together with the prefixes to show the directions. If their language disappears, does not it mean that human beings lose the unique view to the world? Finally, let us take a glimpse to an example with writing system. One branch of Tibetan is called Ersu people. They have their characters, which are between real character and picture writing called Shaba characters. Ersu people's scripture is in Shaba. Each page of the scripture tells a story or a piece of event. The knowledge of medicine is typically rich and the herbal medicine is well defined in it. Quite many names of the herbals recorded in it cannot be translated into other language. The prescriptions to deal with sprain are over 160 . However, the methods to make the medicine are not shown in it, but magic. It belongs to family, passed on generation to generation from mouth to mouth. If there are no language speakers, that part of wisdom of human beings may disappear at the same time.

\section{An Introduction to Xiandao}

\section{Xiandao's Identification}

Xiandao People is a small group ethnic group with the population of around 100, leaving at the border area between Myanmar and Yunnan Province, China. Xiandao Language is the one spoken by this group.

It is said that, just before the founding of the PRC, there used to be more than 100 households with over 400 people living in the traditional, long-standing site of Xiandao in China (The number living in Myanmar is unclear). The smallpox epidemic of 1944 reduced the population to less than 100 people. At the beginning of the 1960s, the Chinese government tried to relocate the remaining Xiandao from their remote mountain homes to the places with better conditions of plain land, near a town or a city. They were assigned mainly to live in two villages, half in Meungwo and half in another place. Those assigned to Meungwo stayed in Meungwo, but the other group, not familiar with their new surroundings, moved back to their original village. In 1994, the government again tried to relocate this group by building new houses in a semi-mountainous area called Mangmian. This time, they had all moved permanently to the new site within two years. They all gave up forever the old place and now live in the new area offered by the government. As the experiences of their past 50 years are different and their situation at present is also different, the author will take in the following the group which moved first as "Group A" and the other group as "Group B".

As it is known that there are 56 nationalities in China classified by the government. Xiandao used to be taken as a branch of Jinpo Nationality, which is known as Kachen in Myanmar. Xiandao people were so unsatisfied with the classification by the government that it was switched to Atsang years later. So their registration is Atsang now while they call themselves "Xiandao". Interestingly, Xiandao themselves refuse to be regarded as Atsang or Jingpo. When they are asked about their ethnicity belonging, they will answer at once: "We are Xiandao people. We belong to ourselves. We do not belong to any other nationality”.

Xiandao language belongs to Tibetan-Burmese language group, like Jinpo and Atsang. All of them live side by side with each other in Dehong Dai and Jinpo Autonomous Prefecture, Yunan. The three languages share some similarities in language. Since Xiandao cannot be taken as an independent nationality, yet it shares more 
similarities with Atsang both in vocabulary and syntax. The author thinks grouping Xiandao as part of Atsang makes more sense.

\section{Group A of Xiandao}

Great changes have taken place in Group A. Initially, this group continued their traditional practices. They built houses as their predecessors did and continued their entertainment as their predecessors did. In the early 1980s, Xiandao language and its culture were largely intact. People were still practicing their traditions: Women wore their traditional dresses; people sang their own songs and spoke their own language. There was no problem for them to stay in their circle at that time with not much connection to the outside. However, after the open policy started in the 1980s, especially in recent 10 to 20 years, modernization has stimulated mainstream culture and ethnic group's culture as well. This is a general phenomenon in modern history and society. Almost all of them now speak Chinese instead of their own traditional language. What people can see there now are new houses, small hotels, stores, karaoke rooms, small reading rooms, and VCD rooms, internet bars. Some of the owners are Xiandao people. You can find telephones everywhere. All people, old or young, male or female, have their cellphones. That is to say you can get in touch with the outside anytime, anywhere if you want to. One can hardly feel that one is at a border area inhabited by minority people. Before the 80s, it took more than a week for them to get to Kunming, the provincial capital city. Now it only takes one day to come to Kunming and return back to their village by plane. After the highway has been built, it takes only about 10 hours by bus to come to Kunming.

Children now can have good education. They go to school run by the government. The more education they get, the less ability they will have of their native language. One of the families the researchers visited has three children. The children cannot speak Xiandao language, although the oldest child can understand some Xiandao. The other children can hardly understand anything. The youngest child is a college student. Her first language is Chinese. She can also speak her second language fluently. Yet it is not Xiandao, it is English. She said she has no need to speak their language anymore, because even the older people rarely use it.

\section{Group B of Xiandao}

The other group, which moved to the present village in the middle of the 90s, is with the population around 50. The way they walk is also different, even though the two groups used to live in the same village and share the same language and the same tradition. It seems they have not been influenced by modern culture so much.

The houses built by the government for this group of Xiandao people are side by side with Jingpo nationality. They have been influenced soon after they got to the new site. They are getting closer and closer to Jingpo. Xiandao language is losing its vitality and shifting to Jingpo language.

This is a special case in China now. It seems a bit strange to many people as minority nationalities are getting closer to the dominant language and culture. But the border area is different in some ways. Jinpo is a very powerful branch in Myanmar. It used to be very powerful with strong army in the area inhabited by other minorities in China. The influence of its culture to the nearby ethnic groups cannot be ignored. Providing that many ethnic groups had no idea about country or nations in the past, quite some people around took Myanmar as their centre and metropolitan. Now, the Jingpo of two countries still get along with each other very closely and spend their traditional festivals together very often. Jingpo nationality keeps its influence on the nearby ethnic 
groups, especially in religion.

Jingpo, both who live in China and Myanmar, are Christians. Influenced by the Jingpo, all these Xiandao villagers are Christians as well, except one who used to serve in the army, and they go to church on Sunday. It is now less than 10 years after the Xiandao people moved to the present village. They read the Bible in Jingpo writing as they themselves have no writing and sing hymns in Jingpo language. They hold their weddings in the church. Priests officiate their funerals. They name their children with biblical names, such as Dawei, which means "David" in Chinese.

\section{Language Vitality of Xiandao}

Since the Group A which moved in the 60s has shifted the language to Madarin Chinese, this section only concerns Group B, who moved to the present village in 1995. Group B has 43 people in all, among whom three women are Jingpo and two men are Han. If the nine criteria by UNESCO to evaluate are used, all of them are negative. In the fieldwork there the author had an exam of their language vitality by talking with the Xiandao villagers one by one so as to evaluate the vitality in another aspect. The author paid more attention to their family language usage and how they communicate with each other. Findings are as follows:

(1) The number of people with Xiandao as their first language is decreasing.

Table 1

First Language of the Xiandao People

\begin{tabular}{llll}
\hline Age & Xiandao language as their first language Jingpo language as their first language & Chinese as their first language \\
\hline Above 50 & 7 & 0 & 0 \\
$40-49$ & 5 & 1 & 0 \\
$30-39$ & 3 & 2 & 1 \\
$20-29$ & 2 & 5 & 1 \\
$12-19$ & 2 & 8 & 0 \\
Below 12 & 1 & 5 & 0 \\
\hline
\end{tabular}

From Table 1, it is clearly that the age of the people with Xiandao language as their first language is older and the amount is decreasing. On the contrary, more and more Xiandao people begin to speak not in their own mother language but in Jingpo, and speak Jingpo language as their first language.

(2) Pure native language speaking family are declining.

It can be seen from some families.

Family One: Jingpo is spoken at home.

YUE Ma-ka, mother, Jingpo woman (Her husband was a Xiandao man, but has been dead.): Jingpo is her best language. Chinese is her second language. She can speak Xiandao, but not so well.

YU Tin-nan, the oldest son, can speak three languages: Jingpo, Xiandao, and Chinese. Among them, Jingpo is his best.

YU Guo-pang, the second son, is almost the same as his older brother.

YU Weng-pang, daughter, can speak Jingpo well and a bit Xiandao. She began to speak Chinese when she went to school at the age of seven.

Family Two: More Jingpo and little Xiandao at home. 
JING Ma-rui, mother, is good at both Jingpo and Xiandao languages. She speaks both languages at home with her children. Comparatively, she uses Jingpo more often while her husband spoke more Xiandao language when he was alive.

YANG Shi-nan, the oldest son, can speak Jingpo, Xiandao, and Chinese languages, but Jingpo language is more often used.

YANG Kun-sang, the second son, is almost the same as his older brother.

YANG Ma-pang, the only daughter of the family, seldom speaks Xiandao language. She usually speaks Jingpo language.

YANG Ma-wang, the youngest, can hardly speak Xiandao language.

Family Three: Mixture of two languages at home.

CUN La-li, father, is good at Jingpo and Xiaodao language. He uses two languages at home.

YU Ma-lu, mother, prefers to speak in Xiandao at home. Yet she can talk with others in Jingpo language.

YU Ma-zhu, the oldest son, likes to speak in Jingpo. When his mother speaks Xiandao language with him, he often answers with Jingpo language.

YU Ma-she, the second son, is with the same habit as his brother.

(3) People's competence of native language is lower.

Before relocation, all Xiandao people spoke Xiandao language. There were no exceptions. Now about $10 \%$ of people do not often speak it and 5\% cannot speak it. They used to talk and communicate in Xiandao no matter at home or in the village.

The researchers were lucky to have a talk with the oldest Xiandao woman who was over 80 years old. She said the people of her generation used their language widely. No matter where they went, where they were, they would speak in their own language when they met Xiandao people. But now it does not work. She can speak only with the aged people with her mother language. "I speak Xiandao in Xiandao language with my grand chidren. They answer me in Jingpo. The children do not follow the traditions of their ancestors. What a pity! It is Xiandao's treasure!” (personal communication, August 5th, 2005) People can see this in any of the families.

The researchers tested the children in their Xiandao language ability. They prepared a list with simple words on it, such as sky, star, mountain, the names of different parts of the body, names of animals, numbers, and so on. When they were asked to speak in Xiandao, they could answer some of the words immediately, some of the words after they thought for a while, and some of the words were what they did not know. Almost no one could count from one to 10 in Xiandao and no one can count from one to 100. The researchers also found the case that several children can understand but cannot speak in their Xiandao language, nor could the children sing in Xiandao. But when they were asked to say in Jingpo, all of them answered correctly and quickly. They can sing so well in Jingpo, both Jingpo traditional songs and Christian songs in Jingpo. As they go to school in Mandarin Chinese, their Chinese is as good as the locative Han children.

(4) The state of the language is declining.

There is no doubt that the language ability of adults is better than children. But in fact they have borrowed more and more words from both Jingpo and Chinese. They themselves acknowledge that. They say that when they cannot find a suitable word they will choose a Jingpo word. If they cannot find in Jingpo language, they will choose Chinese, especially new words such as television and electricity, which in Jingpo are also borrowed from 
Chinese, which is not strange. But it appears more and more frequently that they choose to use Chinese words when they speak Xiaodao or Jinpo, although there are the words that express the same meaning. They say they did manage to use their own language, yet it did not work well. For example, there are no modern words such as "car" or "plane" in their language. They called car "moving house" and called plane "flying house" at the beginning. Gradually, people gave up the saying and use Chinese directly.

\section{Conclusion}

(1) It has been regarded that it takes at least three generations for a language to shift to another. What people have seen in this modern time is that small groups like Xiandao may lose their language as short as 20 to 30 years. Even if they had a chance to be accepted as an independent nationality some day in the future, with the disappearing of their language, nothing can be a better evidence to show what they are. Xiandao is not the only or the rare case. There are about 10 ethnic groups with the population of several hundreds, which also have their own languages. Their language will have less and less vitality as Xiandao with no doubt. Their language may also die some day without being known. With the loss of their language, their identification and real being will become forever a historical mystery. Then people may never know who they were and where they came from.

(2) According to UNESCO's major evaluative factors of language vitality, there are nine criteria. It is very helpful when researchers do the research at bigger nationality. But to a small ethnic group with no writing system like Xiandao, researchers can simply evaluate from the family language. If the family language is not their traditional language spoken by their old generation, it shows the language has little vitality that it may disappear soon if people do not find a way to rescue and preserve it.

(3) The adopted languages that people choose to speak are usually dominant official languages. But the research group have to notice that at the bordering area, some other language which may be an important one at the local area, will be their choice as well. It is of course Mandarin Chinese in China. But there are some other languages of large population speakers that small local ethnic groups are willing to choose to use, which also accelerates the loss of a language.

(4) It is well known that promoting cultural diversity is the essential pre-requisite of the successful development of humankind. Therefore, it is very important to protect the diversity of the language ecology because a language transmits culture. Diversity of language means diversity of culture, and through language, culture can be passed on to successive generations. To protect and save the dying language is urgent, but it is not the business of native speaker and linguists only. It is the business of every one. In China, generally speaking, things will be done successfully if the government decides to do. In recent days the government of Kunming, capital city of Yunnan Province, is spending three billion to plant flowers to take the place of trees in the city. Is it possible just to take one tenth of the three billion to help keep the data of the dying language? Is it possible to train at least one scholar of each language so as to help with their native language and culture? Saving the disappearing language has become the "Sword of Damocles" to the government and all the human beings.

\section{References}

DAI, Q. X. (1985). Voiceless nasals of Atsang language. Minority Languages in China, (2), 11-15.

DAI, Q. X., \& WANG, C. H. (2003). Etymology and endangered tendency of Xiandao language. Minority Languages in China, (3), $1-10$. 
LUO, X. S. (1999a). An introduction to modern Chinese. Kunming: Yunnan People’s Publishing House.

LUO, X. S. (1999b). Modern linguistic theory. Kunming: Yunnan People’s Publishing House.

The Commission of the Grand Sight on the Culture of Dehong. (1999). The grand sight on the culture of Dehong profecture. Mangshi: National Publishing House of Yunnan.

WANG, C. H. (2004). A case study on endangered language of Xiandao from synchronic type by contrast. Journal of Central University for Nationalities (Philosophy and Social Sciences Edition), 31(3), 116-118.

YUAN, Y. (2000). The feature of bilingualism of Atsang nationality and its causes. China's Language Study, 36(2), 36-41.

YUAN, Y. (2001). Language contact and language change: Atsang language as a case. Beijing: Minority Publishing House.

YUAN, Y. (2002). Mutual complement and competition in language contact. Language, Writing and Application, (1), 95-99.

YUAN, Y. (2005). The discussion of language usage in multiracial co-residence regions. Journal of Yunnan Normal University, 37(4), 77-82. 